\title{
El año histórico de 1968. Diez acontecimientos que cambiaron el mundo.
}

\author{
RICARDO RIBERA \\ Departamento de Filosofía \\ Universidad Centroamericana (UCA)
}

San Salvador

\begin{abstract}
The author revierws the main facts of that year: from the death of Che Guevara, the student revolt known as "the French May" and the Chinese cultural revolution; the offensive of Tet in Vietnam and the protests against the war in the Asian country; the students massacre in Tlatelolco square in Mexico, the teacher's strike in El Salvador and the Episcopal Conference in Medellin, Colombia; the beginning of computer nets - an antecedent to Internet-and the conquest of the moon in the context of the spacial race. These were key events to understand the present and the future. A synthesis year in the century, a reflex of $20^{\text {th }}$ century, 1968 is a very suggestive year.
\end{abstract}

Si existe un año en el siglo XX que pueda significar la síntesis de lo que fue la centuria, éste es el de 1968. Una serie de eventos que acontecen en ese año resultan de gran importancia. Unos aparecen como resultado de cierta acumulación histórica, otros son significativos por la serie de consecuencias que acarrearán, otros más muestran ser expresión y síntoma de las hondas contradicciones que atraviesan el siglo. Varias de las claves del siglo aparecen concentradas en la coyuntura que representa 1968.

El año histórico de 1968. Diez acontecimientos que cambiaron el mundo. 
No hay una razón por la que eso deba ser así. No había a esa altura de los tiempos un proceso de historia mundial de una entidad tal que justifique tal coincidencia. Muchos de los acontecimientos que se dan en 1968 son más bien fruto de procesos nacionales o regionales. En la medida que la globalización y la interdependencia avanzan tendrá probablemente vigencia que la humanidad toda ejerza en un futuro como protagonista y sujeto de un único proceso histórico universal. De modo tal que coyunturas como la de 1968 aparezcan como consecuencia directa de la maduración de un proceso único que las esté determinando. Pero plantearlo así para el siglo XX tendría tan poco de científico como quien pretendiera que la coyuntura de 1968 obedece a una conjunción especial de los astros en el cielo. No obstante, aun reconociendo el papel que el azar, la simple casualidad, tiene en la historia, no deja de resultar inquietante y extraño un año histórico tan repleto de acontecimientos y significados como éste de 1968.

Considerarlo "año histórico" implicará no ceñirnos estrictamente a la cronología que impone el año calendario. $O$ sea, no necesariamente comenzará el primero de enero y terminará el 31 de diciembre, sino que su acotación vendrá determinada por sus contenidos y significado. Así como el historiador Immanuel Wallerstein al siglo XVI, en tanto siglo histórico, lo hacía empezar en 1492, año del descubrimiento del Nuevo Mundo e inicio de la conquista, y lo consideraba concluido en la década de 1590 cuando España ha completado su imperio colonial pero ha perdido la hegemonía del sistema mundial que ha ayudado a conformar. O la interpretación de otro historiador, Eric Hobsbawm, quien al considerar al siglo XIX abarca desde 1789, el año de la revolución francesa, hasta 1914, cuando estalla la Gran Guerra. Para dicho autor, a este "siglo largo" le seguirá un "siglo corto", el XX, que comenzando tardíamente en 1914 culminaría de manera anticipada en 1991, al derrumbarse la Unión Soviética y finalizar con ello la guerra fría. Independientemente de si coincidimos o no con dichas interpretaciones lo que nos interesa es la conceptualización de un tiempo histórico con sus propios ritmos, diferente a la cronología del tiempo calendario.

A la luz de esos ejemplos, con respecto al año 1968 nos tomaremos una licencia similar al considerarlo "año histórico": vamos a incluir algunos eventos de finales de $1967 \mathrm{y}$ otros que datan de inicios de 1969. Se trata, por tanto, de un año histórico con algo más de doce meses. Es un período en el que de un modo particularmente intenso se realiza la historia, 
culminando ciertos procesos y dando inicio a otros, caracterizado por sus contenidos y significación. La sucesión de hechos históricos trascendentes se ubica en ciertos países de capitalismo desarrollado, en otros del campo socialista y en varios del Tercer Mundo. Los escenarios se desplazan por el continente americano, por Europa y Asia. En cambio no hay un protagonismo africano relevante en el año histórico de 1968. Es casual pero resulta sintomático. Africa, el continente excluido por excelencia en los modernos tiempos de globalización, tampoco aparecerá en nuestro año-síntesis. Reflejo de todo un siglo, 1968 se despliega rico en sugerencias.

\section{1.- La muerte del Che Guevara}

La noticia recorre el mundo. Ernesto Guevara de la Serna, comandante de la revolución cubana, más conocido como el Che por su acento argentino que nunca perdió, ha muerto en la selva boliviana. Capturado en combate, herido pero vivo, fue ajusticiado el 9 de octubre de 1967 por órdenes del gobierno de Bolivia. La propia CIA, la agencia de inteligencia estadounidense, se encargará de que el mundo conozca una foto del cadáver del Che. El imperialismo espera que la imagen demuestre el fracaso de la opción guerrillera en América Latina y refutar los posibles desmentidos sobre la muerte del líder izquierdista. Grave error. La fotografía, tomada por un agente norteamericano, muestra al Che tumbado boca arriba, sin camisa, sucio y ensangrentado, con la barba descuidada y una expresión serena en su rostro. Para el inconsciente colectivo se parece tremendamente a la figura de Jesús descendido de la cruz. Las posteriores noticias sobre las circunstancias de su aventura guerrillera, la difusión de su Diario de Bolivia y la extraordinaria biografía del revolucionario harán de él un símbolo de la rebeldía, la solidaridad y la generosidad.

Lo que más impresiona es el hecho de que el Che ha dedicado su vida a luchar por la liberación de pueblos que no eran el suyo. Y, sobre todo, que después del triunfo de la revolución cubana haya abandonado cargos, comodidades y honores, en pos de unos ideales por los que entregó su vida. Personifica todo lo que de altruista, aventurero y romántico puede ser el revolucionario ideal. Muy pronto otra fotografía, la que había tomado al poco del triunfo un humilde fotógrafo cubano en un acto de masas, desde un ángulo ligeramente inferior, en el momento justo en que una ráfaga de viento agita la cabellera del Che, será reproducida por millones y vendida en forma de botones, carteles y camisetas. Ha nacido un mito. El sistema lo banaliza al comercializarlo, al transformarlo en mercancía, al

El año histórico de 1968. Diez acontecimientos que cambiaron el mundo. 
rebajarlo al nivel de una moda. Sin embargo, el ícono es símbolo de postura contestataria, rebelde, inconformista. No cualquiera va a gustar de usar una camiseta con el rostro del Che, gesto que compromete e identifica, no tanto en cuanto a una posición política, a menudo más como postura vital. Toda una generación, la juventud de los sesenta, se identificará con la imagen del Che, en una época en que "la izquierda estaba de moda", mientras los símbolos conservadores y burgueses eran puestos a la defensiva ante la crítica contracultural. Todavía hoy, casi cuarenta años después, en tiempos de auge ideológico conservador, la foto del Che sigue siendo reproducida y portada como un estandarte por jóvenes que han nacido mucho después de la coyuntura que comentamos.

Para la revolución cubana la gesta del Che presentaba algunos visos incómodos. Era el fracaso de una política de promoción de la revolución que había comenzado con la activa participación cubana en la guerrilla venezolana, reprimida ferozmente hasta su derrota militar, que culminaba ahora con el naufragio del experimento en Bolivia. Las tesis del foco guerrillero, capaz por sí solo de atraer y movilizar a las masas hacia la lucha revolucionaria, llevaban al desastre. El francés Regis Debrais, que acompañó al Che en Bolivia, lo analizaría en una trilogía titulada "La crítica de las armas". Pero la implantación de fuerzas guerrilleras en casi toda América Latina era una realidad, ante la cual la intromisión cubana podía resultar contraproducente. Fidel Castro asumirá la lección histórica de que la revolución no es algo que pueda "exportarse", al menos no en el continente latinoamericano, por más que a los propios intereses de defensa de la isla le convenga una participación militar y fogueo constante en los campos de batalla contra el imperialismo. En adelante retomará el impulso inicial del propio Che Guevara cuando éste fue al Congo a apoyar la revolución independentista, enfocando el apoyo internacionalista cubano en las luchas de liberación del continente africano (Angola, Namibia, Mozambique, Etiopía).

Una segunda preocupación de la revolución cubana fue desmentir las versiones que empezaron a propalarse sobre supuestas disensiones entre el Che y Fidel, las que habrían motivado la salida de aquél. La posición oficial del régimen desde entonces fue afirmar que el proyecto de Bolivia era una decisión personal de Guevara (ha de recordarse su escrito cuyo título era como un eslogan: "iCrear uno, dos, tres... muchos Vietnam!") y que el régimen castrista le dio todo el apoyo que solicitó y que necesitaba. $\mathrm{Al}$ mismo tiempo las autoridades cubanas han refutado siempre el supuesto 
trotskismo del pensamiento político del Che. Sus posturas críticas a la teoría y práctica soviéticas fueron poco difundidas hasta el desplome de la Unión Soviética, trás lo cual han salido a la luz, amparadas por declaraciones y documentos desconocidos hasta entonces. Ahora hay estudios sobre el pensamiento económico del Che y sobre su concepción de la construcción del socialismo, donde aparece claramente distanciado de la ortodoxia soviética, en la búsqueda de modelos alternativos de economía y sociedad, con preocupaciones humanistas desconocidas en los modelos de "socialismo real".

Por tanto, tenemos, no uno, sino varios Che Guevara, de modo que hoy día es posible reivindicar su legado desde posiciones políticas disímiles y hasta contradictorias. No obstante, por sobre las discrepancias en las interpretaciones del marxismo-leninismo o en la construcción de un sistema socialista que como prioridad busque hacer surgir al "hombre nuevo", se impone desde siempre la imagen menos compleja, pero exacta, del "guerrillero heroico", del militante de la lucha antiimperialista inclaudicable. Y así será mientras el imperialismo siga campando por el mundo, provocando la resistencia de los pueblos, sin importar las decepciones que los distintos modelos de socialismo "real", o incluso irreal, hayan generado. La imagen del Che como modelo de entrega desinteresada y generosa, de lucha hasta las últimas consecuencias seguirá presente en el imaginario de los pueblos. Es una de las herencias del año histórico de 1968.

\section{2.- El mayo francés.}

Durante más de un mes los estudiantes universitarios de París y otras ciudades francesas tuvieron en jaque al gobierno derechista del duro general De Gaulle. La revuelta, iniciada en asambleas en los recintos universitarios y trasladada rápidamente a las calles, levantó barricadas y aisló del resto de la ciudad el céntrico Barrio Latino, habitado mayormente por estudiantes y extranjeros. La policía se veía incapaz de reprimir el movimiento sin causar una matanza inaceptable. Al fin y al cabo, tras las barricadas no había humildes obreros desarrollando una lucha de clases, sino hijos de la burguesía y la pequeña burguesía, la generación a la que tras su paso por las aulas universitarias le correspondería en un futuro asumir las riendas de la nación.

Pero el gobierno carecía de alternativas a la respuesta policial represiva. Negociar una salida era impracticable pues el movimiento de los jóvenes 
radicalizados no tenía un liderazgo definido con quien sentarse a una mesa de negociación y presentaba más bien contornos ideológicos anarquistas. Tampoco planteaba peticiones concretas y plausibles a las que pudiera cederse o ser objeto de un regateo. Era el conjunto de la sociedad burguesa, de sus valores y estilo de vida, lo que era cuestionado. La política del sistema era criticada ferozmente, pero también aspectos de la vida cotidiana, como el consumismo o la doble moral sexual y familiar. El movimiento tenía más visos de un malestar generacional, profundo e inadvertido hasta entonces, que de una revolución en el sentido marxista o clasista del término.

Algunas de las pintas en los muros reflejaban el espíritu de esta rebelión juvenil: "La imaginación al poder"; "Prohibido prohibir"; "iEspantar a los burgueses!"; “iAsaltar el cuartel general!”. La sociedad reaccionó desconcertada y asustada. La brecha entre las generaciones, el desconocimiento del sentir y pensar de los jóvenes, aparecía de repente como un abismo que dividía en dos a la nación. Jóvenes obreros promovieron asambleas de fábrica, al margen de las organizaciones sindicales, $y$ en algunos casos consiguieron forzar huelgas de adhesión a la revuelta estudiantil. La mayor empresa francesa en número de trabajadores, la estatal fabricante de automóviles Renault, se declaró en huelga pese a la oposición del sindicato comunista. Los dirigentes del PCF, el Partido Comunista Francés, se ofrecieron como mediadores y fueron rechazados. También el PCF era acusado de "ser parte del sistema".

De hecho, uno de los oradores estudiantiles más conocidos, Daniel Cohn-Bendit, unos meses después de terminado el alzamiento publicó un libro con un título revelador: "El izquierdismo, remedio a la enfermedad senil del comunismo". Con ello parafraseaba e invertía el sentido de una famosa obra de Lenin: El izquierdismo, enfermedad infantil del comunismo. Los defectos, peligros y desviaciones del radicalismo izquierdista que el dirigente bolchevique criticara en los primeros años tras el triunfo de la revolución de octubre, eran ahora reivindicados por unos jóvenes desencantados con la burocracia de los partidos comunistas occidentales y el revisionismo del régimen soviético. De tal manera la izquierda tradicional resultaba rebasada política e ideológicamente.

Los jóvenes participantes del "mayo del 68" no eran un puñado de alocados. Estaban airados, incluso desesperados, pero eran gente culta e informada, que discutía y leía a los sociólogos, a los politólogos, a los filósofos. Jamás la filosofía había jugado un rol tan directo y determinante 
en los acontecimientos sociales e inspirado un movimiento social como en 1968. Herbert Marcuse, el brillante crítico de la civilización posindustrial y de la cultura de masas (Eros y civilización y El hombre unidimensional) volaría a París desde su residencia en Estados Unidos aquel mayo del 68 y sería recibido como un héroe por los jóvenes rebeldes. También sería aclamado Ernst Bloch, con más de setenta años, percibido como "uno de los nuestros" por la multitud veinteañera que se identificaba con el autor de El espiritu de la utopía y El principio esperanza. Igual los filósofos franceses Jean Paul Sartre (El ser y la nada) y Simone de Beauvoir, esposa del anterior y teórica feminista ( $E l$ segundo sexo). Cuando manos anónimas escribían en los muros "Lo personal es político" o, más provocadoramente, "Cuando pienso en la revolución me entran ganas de hacer el amor", probablemente se inspiraban en estos y otros autores. Una revolución en la vida cotidiana y en las relaciones personales, no sólo en las estructuras, es lo que demandaban los rebeldes parisinos del 68.

Cuando el movimiento cedió, agotado por el acoso policial y la falta de alternativas que sus propias posiciones anárquicas provocaban, se publicó un libro con las fotos de una gran cantidad de "grafittis" (frases pintadas en los muros). Una bien representativa dice así: "Tomo mis deseos por realidades porque creo en la realidad de mis deseos". Pero tal vez la consigna más reveladora del alcance y al mismo tiempo las limitaciones del movimiento del mayo francés es la que proclamaba: "Seamos realistas: iexijamos lo imposible!". Tras el juego de palabras y el patente contenido utópico de la frase no había ingenuidad alguna, sino toma de postura política y filosófica. Lo único posible en el marco del sistema son pequeños cambios que rápidamente son neutralizados por el mismo. La experiencia de la clase obrera sindicalizada que tras conseguir un aumento de salarios ha visto repetidamente cómo la ligera mejoría se esfumaba por la inflación, o las luchas por la reducción de la jornada laboral, victoria anulada por la realidad de que los trabajadores pronto necesitan buscar un segundo puesto de trabajo o tienen que aceptar trabajar horas extra, ilustran lo precario e ilusorio de las batallas sociales planteadas dentro de los límites de "lo posible". Aceptar las fronteras de la posibilidad, luchar por meras reformas, no resulta realista porque con ello nada cambia. La utopía, en cambio, consiste en plantearse como objetivo "lo imposible" porque se considera que en otro sistema de relaciones ello fuera posible. La lucha por la utopía consiste en pugnar por el traslado de las fronteras, por ampliar el horizonte de la posibilidad, para volver posible lo que en el marco actual es imposible. 
La radicalidad teórica del mayo francés no resultó fructífera en Francia, donde no dejó mayores secuelas políticas una vez pasada la tormenta del 68. En cambio sí produjo consecuencias en un país vecino, Alemania. En realidad un movimiento similar aunque menos espectacular se había iniciado ahí un año antes, en 1967. Del mismo procedía el pelirrojo CohnBendit, quien con los años llegaría a ser diputado por el partido de los verdes. El surgimiento del muy masivo movimiento ecologista, feminista y pacifista en los siguientes años tiene raíces históricas en la rebelión estudiantil alemana de 1967. Hubo otras ramificaciones menos determinantes políticamente, pero más virulentas. La influencia más militante de Rudi Dutschke, uno de los líderes más connotados del 67, inspiraría la formación de grupos de guerrilla urbana. El más famoso, con el nombre de Fracción del Ejército Rojo, RAF, sacudiría años después a la acomodada sociedad burguesa alemana con audaces acciones de violencia terrorista: sabotajes, secuestros y asesinatos de prominentes figuras de la banca, la industria y del aparato militar de la OTAN. Desmantelada tras años de persecución policial la "banda Baader-Meinhoff", como la llamó la prensa, representaba la posición anti-sistema más radical en Europa occidental como un cóctel ideológico que podría calificarse de anarcocomunismo. Ese espíritu anarco-contestatario, sin sus expresiones violentas, sigue presente en algunas corrientes que participan hoy del movimiento anti-globalización europeo. No son hijos directos del 68; pero podrían ser considerados sus nietos, pues de ahí proceden.

\section{La primavera de Praga y su aplastamiento}

Paralelamente a los acontecimientos del mayo francés, que galvanizó el descontento de los estratos juveniles en Europa occidental, al otro lado de "la cortina de hierro" (según la expresión de Churchill), en los países de Europa del Este, las expectativas se levantaban en torno al experimento de reforma del socialismo emprendido por las autoridades checoslovacas. Siguiendo el lema enunciado por el sociólogo Radovan Richte de generar "un socialismo con rostro humano", el propio Secretario General del Partido Comunista y jefe del gobierno checo, Alexander Dubcek, lanzaba un audaz plan de reformas para democratizar el sistema. Incluía modalidades de economía mixta, impulsando empresas privadas a la par de las estatales. Lo que más llamaba la atención del Programa de Acción promulgado en abril era la proclamada intención de "humanizar" el socialismo. 
La iniciativa de las autoridades se ganó rápidamente el apoyo entusiasta de una gran parte de la población y sobre todo de los jóvenes checos. Estos se sentían parte de Europa, sentimiento estimulado por la apertura al turismo occidental, los intercambios estudiantiles y la libertad informativa y cultural, políticas que desde años atrás venía impulsando el gobierno comunista de Checoslovaquia. El país, con un desarrollo industrial superior al resto del campo socialista, contaba también con un vigoroso clima intelectual. Reinaba un ambiente de debate y de apertura mental incomparable con el resto de Europa del Este. La sociedad estaba influida por la labor crítica de cineastas como Milos Forman y Jiri Menzel, de escritores de talla como Milan Kundera o de importantes filósofos de marxismo heterodoxo como el húngaro Georg Lukács. La renovación intelectual precedió y de alguna forma preparó las condiciones sociales para que en Checoslovaquia apareciera y floreciera la gran esperanza que representó la llamada "primavera de Praga" en 1968.

El régimen checo defendía su derecho a impulsar su propio proyecto, en la búsqueda de su identidad nacional y desde su sentimiento de pertenencia a Europa, pero con la necesaria prudencia frente a la superpotencia soviética, al no cuestionar su adhesión al socialismo ni su pertenencia a la alianza militar del Pacto de Varsovia. La represión en 1956 del intento de separación de Hungría dejaba claros los límites que no podían ser traspasados. Tampoco Dubcek, egresado de la Escuela Superior de Cuadros del Partido de Moscú, pretendía hacerlo. Lo que él y su equipo protagonizan es un intento de promover una "perestroika" en el campo socialista, pero casi veinte años antes del ascenso de Gorbachev al poder, poniendo a prueba los alcances y sinceridad de la desestalinización que había iniciado Kruschev y parecía consolidarse con Breznev.

Inicialmente el Kremlin dejó hacer, no sin permanecer atento a la evolución ideológica y política del experimento checo. Pero éste suscitaba la alarma de sus vecinos. Tanto las autoridades de la República Democrática Alemana como las de Polonia temían que pronto surgiría una corriente popular en sus países que reclamaría imitar el modelo de socialismo que se empezaba a impulsar en Checoslovaquia. Finalmente Breznev tomó partido y decidió cortar de tajo las veleidades reformistas checas. Entre el 20 y el 21 de agosto medio millón de soldados y 7 mil tanques de las fuerzas conjuntas del Pacto de Varsovia invadían Checoslovaquia para derrocar el gobierno y tomar presos a los principales dirigentes. La 
población respondió con una amplia campaña de resistencia pasiva. Discutían con los soldados, rusos la mayoría, confraternizaban con ellos y, en una imagen que se repetiría después en Portugal tras el golpe de estado que en 1974 derribó la dictadura militar en aquel país, colocaban claveles en la boca de sus fusiles. De nada sirvió ante la inflexibilidad de las órdenes soviéticas. La sensatez del pueblo checo evitó que se produjera un baño de sangre. Hubo un muerto: un estudiante que se inmoló en Praga meses después en protesta por la ocupación militar del país y el aplastamiento de su autodeterminación e independencia. El sentimiento de impotencia permitió la estabilidad del país que, sin embargo, nunca se resignó a la renuncia de su propio proyecto transformador. De hecho, Alexander Dubcek regresaría a la política al desplomarse el comunismo dos décadas más tarde, respetado como el reformador a quien no le permitieron democratizar el socialismo.

Breznev, que había proclamado en su momento la "coexistencia pacífica" con el mundo capitalista, enunciaría tras el aplastamiento de la primavera de Praga la nueva doctrina con respecto a los países del campo socialista bajo su esfera de influencia: la "soberanía limitada". Los intereses supremos de la Unión Soviética y del socialismo, según tal doctrina política, debían prevalecer sobre la independencia efectiva de los países de Europa del Este. Quedaba así oficializado el sometimiento de los mismos a las decisiones de Moscú, que imponía su propia política imperialista donde así podía hacerlo. Occidente aceptó el criterio de respetar las “áreas de influencia" de cada una de las superpotencias y no intervino de ningún modo en defensa del pueblo y gobierno checos. Explotó con gran eficacia la imagen de falta de libertades y de brutalidad del bloque soviético, alimentando su aparato propagandístico. Los partidos comunistas de Europa occidental reaccionaron con gran disgusto a la intervención militar soviética y tres de los más importantes, los de Italia, Francia y España, la criticaron abiertamente, se distanciaron de Moscú y renovaron su pensamiento y propuestas: había nacido el llamado "eurocomunismo". Tomaría su andadura propia según el "espíritu de Praga".

\section{Auge y fracaso de la revolución cultural china}

1968 será un año decisivo para el futuro de China: por un lado Lin Piao podrá declarar, a inicios del siguiente año, que "la revolución cultural ha triunfado", mientras, por el otro, su derrota viene señalada por el exterminio o absorción en el ejército de la mayoría de los "guardias rojos" que fueron su motor y brazo ejecutor. En realidad, el $\mathrm{IX}^{\circ}$ Congreso de 
Partido Comunista Chino de principios de 1969 se fijó como objetivo "la reconstrucción del Partido" tras la anarquía y el caos generado por la revolución cultural maoísta. Pero sus máximos dirigentes se integraban al Buró Político. Poner fin al experimento todavía costaría varios años de intensas luchas entre facciones. Pero la iniciativa que levantara Mao Tsé tung ya no lograría reponerse y pasaría a la historia como otro fracaso del "gran timonel".

Todo comenzó en otoño de 1965 cuando Mao consiguió del Partido autorización para lanzar una campaña de propaganda para "destruir el antiguo mundo". Desplazado del poder real tras el fracaso económico de "El Gran Salto Adelante", lanzado por iniciativa suya, el experimentado dirigente iba a dar inicio a una audaz maniobra para recuperar su liderazgo en el partido y en el país. Descontento con el pragmatismo reformista de otros camaradas, que priorizaba el crecimiento económico y la eficacia, Mao buscaría apoyarse en las masas para enfrentarlas al aparato burocrático del Partido e intentar reconquistarlo. Acusaría a la dirigencia estatal de estarse convirtiendo en "la nueva burguesía", atacaría por igual a técnicos e ingenieros, a intelectuales y funcionarios del partido. La lucha de clases no había terminado con el triunfo de la revolución socialista y Mao seguía confiando en las masas campesinas como la clase principal, frente a los sectores urbanos que en su opinión tendían a aburguesarse. Defenderá a la juventud china como el grupo social que no estaba corrompido y se apoyará en los estudiantes para lanzar una revolución dentro de la revolución. El Grupo de la Revolución Cultural dirigido por la esposa de Mao organizó una estructura paralela a la del Partido, los "guardias rojos", reclutados sobre todo entre los estudiantes universitarios.

En mayo de 1967 un millón de guardias rojos venidos de todo el país se congregaba frente la Puerta de la Paz Celestial, en Pekín, a escuchar al "gran timonel”: “iDestruid lo viejo, construid lo nuevo!”. La revolución cultural se ponía en marcha en todo el país, bajo la guía del "pensamiento de Mao Tsé tung”. La edición de Citas del Presidente Mao, más conocida como el Libro Rojo, se reprodujo por centenares de millones y se tradujo a la casi totalidad de idiomas conocidos. El maoísmo cobraba notoriedad en el mundo, como una forma de leninismo a la china, provocando debates y en algunos casos escisiones en los partidos marxistas y la fundación de organizaciones de signo pro-chino o maoísta. En todas partes se revitalizaba la opción por la lucha armada y en el Tercer Mundo por movimientos guerrilleros que arraigasen entre el campesinado. El

El año histórico de 1968. Diez acontecimientos que cambiaron el mundo. 
imperialismo, según la definición de Mao, era "un tigre de papel". Se asumían también las críticas a la Unión Soviética, calificada de "socialimperialismo". La lucha ideológica y por la "proletarización" de la militancia se ponían en un primer plano. La revolución cultural china fue mitificada en muchas partes y sus ecos seguirían resonando incluso mucho después de haber sido muerta y enterrada en la propia China comunista.

En 1967 se imponían los guardias rojos en la mayoría de provincias, se destituían a los comités locales del Partido, se encarcelaba a dirigentes y hasta hubo casos de linchamientos. Muchos dirigentes nacionales fueron purgados, incluido Den Xiao ping, el cerebro de la reformas económicas, y enviados a comunas rurales a "reeducarse". Chu En Lai, el Presidente del Consejo de Ministros y compañero de Mao desde la Larga Marcha de la guerra revolucionaria, pudo mantenerse en el cargo pero privado de poder real. Hubo resistencias y en algunas ciudades se dieron auténticas batallas entre fracciones. Las universidades permanecían cerradas, la producción industrial se redujo y la producción agrícola también descendió dramáticamente. Reinaba el caos en toda China.

El propio Mao empezó a tomar distancia del fanatismo e irracionalidad con que grupos de guardias rojos actuaban. Empezaron a surgir rivalidades entre ellos. Mao se apoyó entonces en el ejército para restaurar el orden y reorganizar la producción. Empezará una campaña de denuncia del ultraizquierdismo y se intentará desarmar a los guardias rojos a partir de 1968. Éstos se resisten y terminarán siendo diezmados por el ejército. Éste retoma el control pero se niega a mantener militarizado el país. El Partido ha de asumir nuevamente la conducción. Es así cómo a principios de 1969 casi la mitad del nuevo Comité Central procede de las filas del ELP. Poco a poco son rehabilitados los dirigentes purgados por la revolución cultural. Es un difícil equilibrio de fuerzas, donde los maoístas todavía intentarán en 1973, con una campaña dirigida supuestamente a criticar el pensamiento de Confucio, debilitar la posición nuevamente reforzada de Chu En Lai. Éste conseguió prevalecer y en 1975 puso de nuevo al frente de la conducción económica a Deng Xiao Ping, quien lanzó la línea de "las cuatro modernizaciones". El milagro económico chino y su despegue camino a convertirse en potencia económica mundial empezaba a sentar sus bases, tras diez años de anarquía y virtual guerra civil.

El Presidente Mao, no obstante, mantuvo hasta el fin de sus días el respeto y apoyo de masas, alimentado con un exagerado culto a la personalidad, y nadie en el Partido se atrevió a desafiar su poder. Pero 
tras su muerte en 1976, pocos meses después era arrestada su viuda, Jiang Qing, acusada de conspirar y de ser parte de "la banda de los cuatro" que habría provocado la pesadilla de los años de revolución cultural. Lin Piao, el jefe del ejército que acuerpó la revolución cultural y la hegemonía de Mao, había muerto en 1971 víctima de un extraño accidente de aviación, cuando volaba secretamente a Moscú. China pasaba página a un complicado período de su historia contemporánea, de extremismo ideológico que llevaba a la revolución permanente y a la guerra civil, pero también de rectificación hacia la estabilidad, la moderación y la modernización, como ha demostrado en el siguiente cuarto de siglo.

\section{La ofensiva del Tet en Vietnam}

1968 significó un punto de inflexión en la guerra de Vietnam, señalando un antes y un después. La presencia militar norteamericana estaba en esa fecha en su punto más alto: 536 mil soldados. Sin embargo, la ofensiva guerrillera del mes de enero, coincidiendo con las festividades del Tet que marcan el inicio de la época lluviosa en el trópico vietnamita, cambió la tendencia a la escalada militar y a partir de ese momento Estados Unidos buscará la forma de retirarse. El fracaso del intervencionismo imperial se ha hecho patente e insostenible.

El involucramiento estadounidense en el conflicto vietnamita comenzó en 1961 con la Administración Kennedy, quien invocó la "teoría del dominó": si todo Vietnam cae en manos comunistas, caerá toda Indochina y le podría seguir el resto de Asia; con ello el comunismo se volverá imparable. Lo que estaría en juego, según dicha visión, sería "la defensa del mundo libre". Hasta 1965 la estrategia norteamericana se basaba en el envío de "asesores" militares y grandes volúmenes de pertrechos bélicos al gobierno pro-occidental de Vietnam del Sur, enfrentado a una guerrilla que apoyaba el régimen comunista de Vietnam del Norte. La reunificación del país prevista por los acuerdos de Ginebra tras la retirada francesa de Indochina en 1956 se había frustrado con el golpe militar que impuso un gobierno de la minoría católica en Saigón, en un país budista en su gran mayoría. En 1964 Estados Unidos incrementó a 23 mil efectivos su presencia y en 1965 ésta ya alcanzaba la cifra de 184 mil soldados. La superpotencia se había metido en una trampa ("empantanamiento" fue la expresión utilizada por los críticos) a la que no hallaba más salida que proseguir en su escalada bélica. De 25 mil ataques aéreos en 1965 se había pasado a 180 mil en 1967; las 63 mil toneladas de bombas lanzadas en 1965, para 1967 se habían convertido en 226 mil. Al final Estados Unidos

El año histórico de 1968. Diez acontecimientos que cambiaron el mundo. 
habría arrojado cuatro veces más explosivos que en toda la segunda guerra mundial.

El optimismo oficial norteamericano de los primeros años, basado en su superioridad tecnológica y militar, había ido desvaneciéndose ante una guerra irregular en la que el conocimiento del terreno y el apoyo de la población resultaban factores decisivos. Si el general Maxwell Taylor había enunciado eufórico un planteamiento vencedor, basado en "las tres M" (Men, Money, Material; hombres, dinero, material de guerra) la realidad lo había desmentido y su sucesor en el terreno, el general Westmoreland, anunciaba una estrategia mucho más sombría: "regresar Vietnam a la Edad de Piedra". Pero en verdad, Estados Unidos estaba limitado por las características de un conflicto en el Tercer Mundo, con una potencia no nuclear y presionado por la opinión de sus aliados y la del público. Le era vedado utilizar el arma atómica o invadir Vietnam del Norte.

Sus esfuerzos por "pacificar" el país enfrentaban la fiera determinación de la guerrilla del Frente de Liberación Nacional, FLN, denominada por Estados Unidos "vietcong" (comunistas vietnamitas). No todos lo eran: había un fuerte componente nacionalista en la lucha de una nación que se veía invadida por un ejército extranjero, al que no podía sino considerar como continuación de la opresión colonial. Se correspondía con el concepto de "guerra patriótica de todo el pueblo" que guiaba a las tácticas del general Giap, el máximo jefe militar de Vietnam del Norte, estratega de la victoria sobre Francia y ahora de la guerra contra el imperialismo estadounidense. Para el pueblo viet ésta no era sólo parte de la confrontación propia de la guerra fría entre el socialismo y el capitalismo; también estaba en juego la dignidad e independencia de su país. La inmolación de monjes budistas exigiendo la retirada de Estados Unidos lo demostraba de manera rotunda y descalificaba la propaganda anticomunista con que la gran potencia justificaba su intervención.

La gran ofensiva del Tet agarró a Estados Unidos de sorpresa por su contundencia. Según sus cálculos, la guerrilla estaba debilitada y agotada, sólo sería cuestión de tiempo su derrota final y creía imposible que pudiera lanzar una campaña de gran envergadura. Pero el FLN atacó simultáneamente más de un centenar de poblaciones. Divisiones militares del Norte cruzaron la frontera y atrajeron sobre sí al grueso de los refuerzos norteamericanos. Lograron, con enormes bajas propias, tomar la ciudad imperial de Hué, capital histórica en la cintura del país. Su conquista era un símbolo de gran importancia psicológica para el pueblo 
viet. Mientras tanto, el FLN sorprendía con una ofensiva en toda regla en el sur desde la superpoblada zona del delta del Mekong. La encabezaban divisiones de tanques, desmontados pieza por pieza y trasladados secretamente durante años por la legendaria "ruta Ho Chi Minh", desde Vietnam del Norte hasta el extremo sur del país. Desenterrados y ensamblados nuevamente, su efecto sorpresa fue decisivo. Se llegó a combatir casa por casa en la propia Saigón, la capital, a escasas cuadras de la embajada de Estados Unidos.

Aunque la ofensiva del Tet tuvo un desenlace militar incierto pues la guerrilla no logró tomar el poder y sufrió enormes bajas, de un tercio de sus efectivos, sin embargo fue una victoria política y propagandística decisiva. Cambió la percepción en el mundo sobre la marcha de la guerra de Vietnam: Estados Unidos la estaba perdiendo. El presidente Johnson, agobiado por una opinión pública cada vez más crítica, anunció que no se presentaría a la reelección. El candidato por el Partido Republicano, Richard Nixon, centró su campaña en la promesa de poner fin a la guerra de Vietnam y resultó electo. Inició la reducción del número de tropas y anunció la nueva estrategia de "vietnamización" del conflicto. El ejército vietnamita del Sur quedaría a cargo, al tiempo que se iniciaban negociaciones, que en realidad se reducían a discutir las condiciones de la retirada de Estados Unidos. Culminarían en 1973 y la caída del régimen del Sur sería ya sólo cuestión de tiempo. En 1975 caía Saigón, era rebautizada con el nombre de "ciudad Ho Chi Minh", el país era reunificado, todo él bajo régimen socialista y con su capital en la norteña Hanoi. El imperialismo había sido derrotado.

\section{Las protestas por Vietnam, el movimiento hippie y el festival de Woodstock}

La derrota de Estados Unidos fue obra del pueblo vietnamita, que pagó un precio muy elevado: cerca de un millón de muertos. Pero, sin duda, resultó determinante también el vuelco de la opinión pública norteamericana contra la continuación de esa guerra. Se cobró 58 mil vidas de jóvenes estadounidenses y destrozó el futuro de unos $300 \mathrm{mil}$ que fueron heridos o mutilados. A la altura de 1968, tras ocho años de intervención, los Estados Unidos habían perdido su imagen de potencia anticolonialista y pacifista. Aparecían ahora a los ojos del mundo y de buena parte de su propia población como una potencia imperialista y agresiva. Su política exterior había entrado en una crisis de legitimidad. Era uno de los efectos del "síndrome de Vietnam".

El año histórico de 1968. Diez acontecimientos que cambiaron el mundo. 
A ello contribuyó enormemente la difusión de fotos, artículos periodísticos y reportajes televisivos que daban cuenta de atrocidades cometidas por sus propias tropas o las de sus aliados. La foto de una niña vietnamita de nueve años, que corre desnuda con el cuerpo en llamas mientras huye de un bombardeo con napalm, estremeció a la opinión pública. O la ejecución sumaria de un guerrillero recién capturado, en plena calle y con toda frialdad, por el jefe de la policía de Saigón, filmada y transmitida por la televisión norteamericana. Asimismo la matanza de los pobladores de la aldea Mi Lay, en su mayoría ancianos, mujeres y niños, que protagonizó una unidad de infantes de marina, cubierta por corresponsales de guerra occidentales y ampliamente documentada. Las autoridades militares de Estados Unidos insistían en que se trataba de actos aislados, que los responsables fueron juzgados y condenados. De nada servía. Los periodistas iban tras la noticia y, obviamente, no lo era si una patrulla operaba sin incidentes y siguiendo las normas. Se trataba de la primera guerra televisada en directo y el alto mando no había medido el impacto de las noticias de Vietnam sobre su retaguardia. Los esfuerzos oficiales por ocultar las bajas propias o los abusos que ocasionalmente cometían sus tropas estaban condenados al fracaso. Un periodista lo resumió con ironía: "El objetivo del presidente Johnson, al parecer, era: cómo hacer la guerra sin que el New York Times lo notase”. La opinión pública se volcó contra la guerra.

Una gigantesca manifestación contra la guerra de Vietnam tuvo lugar en Washington, frente al Pentágono, en 1967. Otras 200 mil personas repetirían la demostración el año 1969. En estas protestas jóvenes en edad militar, en un acto de desobediencia civil, quemaban públicamente sus cartillas de reclutamiento. La impopularidad del sistema de reclutamiento se debía también a que los jóvenes de clase media y alta eludían fácilmente ir a Vietnam. Allá eran enviados mayoritariamente los pobres y los miembros de las minorías raciales. Los afroamericanos que representaban el $11 \%$ de la población total, en cambio suponían el 31\% de las tropas destacadas en Vietnam. Por otra parte, nadie quería ir a morir en una guerra que parecía absurda, a miles de kilómetros, en las selvas de un país desconocido, por motivos tan abstractos como "la defensa de la libertad".

No es de extrañar, por tanto, que creciera la influencia de corrientes contraculturales y pacifistas. La más importante en la época era sin duda el movimiento hippie. Nacido a inicios de la década, inspirado por 
aventureros nómadas como Jack Keruac y por las influencias de filosofías orientales, era un movimiento juvenil que vivía en comunas al margen de la sociedad consumista. Su lema "amor y paz" cobraría sentido concreto ante la evolución de la guerra de Vietnam y se transformaría en el conocido eslogan contestatario "haz el amor y no la guerra". Aunque los hippies auténticos eran una pequeña minoría, no dejaban de ser admirados e imitados por una generación entera de jóvenes. Era una revolución en los valores: amor libre, espontaneidad, rechazo a las normas sociales, pacifismo, respeto a la naturaleza, drogas y creación artística.

En los laboratorios de la Universidad de Berkeley, en San Francisco, había nacido el LSD, droga sintética alucinógena que inspiró la nueva corriente del arte psicodélico. La marihuana y otras drogas relativamente suaves se pusieron de moda entre la juventud y su uso era considerado en la época como un signo de rebeldía. Eran consumidas de manera ostentosa por la mayoría de las estrellas de la música rock, verdaderos líderes juveniles en los sesenta. Todo ello formaba parte de la "contracultura" o "underground" que contradecía los valores y la hipocresía imperantes en la sociedad, por ejemplo, la existencia de drogas permitidas, como el alcohol y el tabaco, tildadas de más nocivas que algunas de las ilegales. Igualmente con el tema de la sexualidad.

En este ambiente surgió la convocatoria a tres días de festival musical en Woodstock, en la costa este, en la primavera de 1969. La concurrencia masiva sorprendió a sus organizadores y desbordó la infraestructura prevista. Más de 200 mil personas de todo el país se congregaron en el enorme descampado haciendo colapsar toda previsión de instalaciones sanitarias, alimentos, etc. Al público asistente no pareció importarle. Las escenas de jóvenes bañándose desnudos, haciendo el amor o drogándose en público, escandalizaron a una parte del país pero seducían a otra. Los mismos residentes de la zona, humildes granjeros, reaccionaron con opiniones divididas. Para unos los jóvenes eran un escándalo y una molestia intolerables, para otros una expresión de la libertad y del amor a la vida, además de una fuente de ingresos inesperados.

Músicos consagrados como Janis Joplin o Jimi Hendrix participaron en el festival; otros grupos desconocidos se hicieron famosos gracias a él. El tema de Vietnam y su crítica no podía faltar, y algunas actuaciones galvanizaron las protestas contra la guerra. Fue el festival de Woodstock el momento culminante de una época que ya iba camino a ser superada. Pero en su momento marcó una señal inequívoca de que la juventud

El año histórico de 1968. Diez acontecimientos que cambiaron el mundo. 
estaba en Estados Unidos desconectándose de sus autoridades y de los valores socialmente aceptados. Aunque menos politizados que sus compañeros europeos, los jóvenes estadounidenses sin duda coincidían en un caldo generacional común.

\section{La matanza de Tlatelolco}

Los acontecimientos de 1968 en la capital mexicana iban a demostrar el dramatismo que las luchas sociales podían alcanzar en los países periféricos. Eran los estudiantes universitarios, también ahí, los grandes protagonistas. Pero en América Latina una protesta pacífica podía terminar en una masacre. Hubiera sido de esperar tal represión violenta por parte de alguna de las dictaduras militares que asolaban el continente, pero no en México, que junto con Chile y Costa Rica, era de los pocos países latinoamericanos con larga tradición democrática. Ciertamente, el Partido Revolucionario Institucional, PRI, ejercía una suerte de monopolio del poder político de varias décadas pero, heredero de la revolución mexicana, era considerado internacionalmente como una fuerza progresista. Pero en el plano nacional venía mostrando una tendencia al autoritarismo que se exacerbó en la coyuntura del 68.

En la gigantesca Universidad Nacional Autónoma de México, UNAM, los estudiantes iniciaron en el verano de ese año una serie de asambleas para demandar una reforma universitaria. La situación se fue politizando ante la intransigencia gubernamental y las reivindicaciones empezaron a abarcar aspectos de crítica a la política nacional. Pocas semanas antes de la inauguración de los Juegos Olímpicos, previstos a realizarse en septiembre en el Distrito Federal, los jóvenes decidieron tomarse la Plaza de las Tres Culturas, también llamada plaza Tlatelolco, para presionar al gobierno en momentos en que México atraería la atención mundial. Las autoridades habían invertido grandes sumas en los Juegos, de los que esperaban un efecto propagandístico positivo sobre la imagen del país y la atracción de inversiones. La toma de una céntrica plaza por el movimiento estudiantil estorbaba dichos planes. Para los manifestantes era la mejor ocasión de presionar por una negociación con el gobierno. Mas éste prefirió tomar otra línea de acción.

Investigaciones posteriores comprobaron que la policía había logrado infiltrar, incluso a nivel de la dirigencia, al movimiento estudiantil. De hecho, alguno de los oradores en la plaza resultó ser oficial de inteligencia que había penetrado en la organización. De tal modo, el movimiento fue manipulado para provocar una radicalización que justificase la operación 
de represión que ya estaba diseñada y decidida con antelación. Tropas combinadas de la policía y el ejército irrumpieron en la plaza Tlatelolco desde diversos puntos provocando la encerrona de los más de 4 mil manifestantes. Comenzaron los disparos y —en legítima defensa, según las autoridades -las fuerzas del orden abrieron fuego sobre la multitud. Oficialmente el gobierno reconoció 28 muertos y alrededor de doscientos heridos. Pero fuentes independientes y testigos oculares aseguran que los muertos fueron más de doscientos. Se capturó a centenares de personas y la mayoría fue objeto de golpizas y malos tratos. Hubo también varias decenas de desaparecidos, los que se supone fueron asesinados un tiempo después de su captura.

Filmaciones de vecinos y periodistas mostraron la existencia de agentes de civil que se hallaban mezclados entre los manifestantes y que fueron ellos quienes iniciaron los tiroteos. Un guante blanco en su mano derecha, que se colocaron al momento de iniciar el ataque, era la contraseña acordada para evitar ser baleados o apresados por los efectivos gubernamentales. Dichos elementos se encargaron de generar el caos inicial y posteriormente de balear o capturar a determinados líderes estudiantiles. Se trataba de una verdadera maniobra de conspiración gubernamental a fin de golpear al incipiente movimiento opositor, ensañándose con la cara más visible del mismo, que era el movimiento estudiantil. Los investigadores señalan la participación de miembros de la estación local de la CIA en la planeación y ejecución de la matanza. Una película documental realizada en años posteriores muestra imágenes de archivo y entrevista a víctimas y testigos, con una convincente argumentación sobre la responsabilidad del gobierno de la época y del papel de los agentes de inteligencia estadounidenses.

Los trágicos acontecimientos en la Plaza de las Tres Culturas, frente a centenares de testigos que los presenciaron impotentes desde las ventanas de sus casas, derribaron las esperanzas de una posible democratización mientras se mantuviera la hegemonía política del PRI. México mostró una realidad próxima a la vertiente más sombría del autoritarismo latinoamericano. Un vuelco hacia la línea que propugnaban los Estados Unidos según la doctrina de seguridad nacional y de terrorismo de estado, semejante a la seguida por dictaduras militares en el continente, parecía estarse concretando en el país azteca. México, pese a su tradición de asilo y refugio a perseguidos políticos de otras latitudes, aparecía ahora más lejos de París o de Berlín, que de Guatemala o San Salvador. No tanto por geografía, como por la política que estaban adoptando sus autoridades.

El año histórico de 1968. Diez acontecimientos que cambiaron el mundo. 
Más tarde vendrá la ruptura de un ala izquierda del PRI con el partido oficial, que se constituirá en Partido Revolucionario Democrático, PRD. Después, su derrota a manos de la oposición neoliberal del PAN. Son ecos lejanos del desencanto que el prí́smo empezó a generar en 1968. Más de treinta años después de los sangrientos hechos de Tlatelolco y apartado el PRI del poder, se ha podido por fin abrir proceso judicial al ex-presidente Echeverría y a otros altos cargos de su gobierno. La impunidad del genocidio de Tlatelolco puede que finalmente sea superada.

\section{La huelga de ANDES}

El 21 de junio de 1968, un día antes del Día del Maestro, el magisterio nacional de El Salvador se proclamaba en huelga general. El movimiento sería impactante para la sociedad salvadoreña y premonitorio del potente movimiento opositor de masas que se desarrollaría durante la década siguiente. Una de las claves de las revoluciones centroamericanas de los ochenta sería la masividad y beligerancia de un movimiento popular que empezó a gestarse, en el caso salvadoreño, en la coyuntura de 1967-1968. Señala el arranque de la crisis social como consecuencia del fiasco en que derivó el proceso de integración económica de la región, conocido como Mercado Común Centroamericano. Su fracaso provocó la guerra entre El Salvador y Honduras de 1969 y sentaba las bases para la exacerbación de las contradicciones sociales a todo lo largo de la década de los setenta.

La conflictividad social empezó a hacerse sentir en 1967 con el desarrollo de varias huelgas. La de los trabajadores de la fábrica textil IUSA, en febrero, resultó exitosa. En abril una huelga en la empresa metalúrgica ACERO, ubicada en Zacatecoluca, en el interior del país, fue contestada con despidos. Provocó, de inmediato, una huelga de solidaridad. Se sumaron a ella los obreros ferroviarios y los descargadores del puerto de Acajutla y del puerto de Cutuco. Dos días más tarde, las dos principales centrales sindicales hacían un llamado a la huelga general, el cual era seguido en la mayoría de las más importantes empresas. Fuentes sindicales cifraban, tal vez exageradamente, en 35 mil los obreros en paro. La patronal, presionada por el gobierno y por la gremial de la empresa privada, tuvo que ceder. Los despedidos fueron readmitidos. Habían sido dos primeras victorias. En septiembre la lucha de los panificadores fracasó. Pero la clase obrera y la oposición habían levantado su moral y su disposición de lucha. 
En ese clima psicológico fue que el año siguiente los maestros lanzaron su huelga, una medida que sorprendió a la población pues el sector de empleados públicos, del que el magisterio era parte integrante, no se había distinguido hasta entonces por su combatividad, sino más bien por su docilidad. La lucha de los maestros fue recibida con muestras de comprensión y apoyo por el pueblo, a pesar de los contratiempos que la interrupción de la actividad escolar causaba en cada hogar. El movimiento consiguió tan sólo una parte de sus demandas. Pero lo decisivo fue que dejó como resultado la constitución de una fuerte asociación gremial: la Asociación Nacional de Educadores Salvadoreños, ANDES - 21 de Junio. Un año más tarde repetiría la huelga con mayor dosis de experiencia y de organización. Había nacido un importante bastión del bando opositor, que se convertiría en símbolo de lucha y resistencia.

Para la dictadura militar que gobernaba el país desde los trágicos sucesos de 1932, cuando una intentona insurreccional promovida por el Partido Comunista fue reprimida con un genocidio, la toma de conciencia de los maestros era algo muy grave. Junto al cura y al médico, el maestro era parte de "las fuerzas vivas de la nación". Los tres eran la autoridad moral e intelectual en cada pueblo, a la par de la autoridad real del alcalde y del jefe del puesto de la Guardia Nacional. A fines de la década de los sesenta estos reproductores de la ideología dominante, que ayudaban a mantener la ley y el orden en el campo, en muchos lugares se han vuelto críticos del gobierno: el médico porque se ha politizado en las asambleas y movimiento estudiantil de la Universidad Nacional, el sacerdote a menudo transformado en agitador y organizador del campesinado a raíz de los lineamientos del Concilio Vaticano II y de Medellín, así como por la teología de la liberación y, por último, el maestro o la maestra, concientizados a partir de sus propias experiencias de la lucha gremial y de las iniciativas de ANDES. Se empezaba a desarrollar lo que Gramsci llamaba una "guerra de posiciones", o sea, una lucha por la hegemonía ideológica, por imponer las ideas dominantes en la sociedad.

La radicalización del magisterio fue a la par con la de todo el país. Participó de la lucha electoral de 1972, saldada con el fraude que se le hizo a la Unión Nacional Opositora, UNO. A la altura de 1975 la mayoría de su dirigencia votó por la integración de ANDES en el Bloque Popular Revolucionario, BPR, que coordinaba la parte del movimiento de masas que orientaba una de las organizaciones revolucionarias más poderosas: 
las Fuerzas Populares de Liberación "Farabundo Martî", FPL. De hecho, varios de los más connotados dirigentes gremiales del magisterio se afiliarán en el transcurso de estos años a las diferentes organizaciones de la izquierda, llegando a ser dirigentes del FMLN al iniciarse la guerra civil. Así, Mario López será el Comandante Venancio del PRTC, Norma Guevara será miembro de la Comisión Política del PCS, Mélida Anaya Montes con el nombre de Comandante Ana María llegó a ser la segunda en el mando de las FPL, o Leonel González quien encabezó dicha organización desde 1983 y en la posguerra ha sido Secretario General del partido FMLN. Muchos otros se integraron de forma anónima en las filas de combatientes del movimiento de liberación nacional. El conflicto salvadoreño, considerado por Ronald Reagan la "prioridad número uno" de su política exterior, se alimentó de estas raíces sociales que se hundían en su historia.

El magisterio salvadoreño pagó un fuerte precio por ese compromiso político. Más de 400 maestros fueron asesinados o desaparecidos en la espiral de violencia generada desde mediados de los setenta. Varios centenares más tuvieron que irse al exilio para salvar sus vidas. Otros se desvincularon de toda actividad política o gremial. Una vez pasado el conflicto armado, ANDES ha seguido siendo un interlocutor ineludible frente al Ministerio de Educación, aunque ya sin la absoluta preponderancia entre el sector magisterial que había tenido en la coyuntura del 68 y la década siguiente. No obstante, al momento de la entrega anual de las Medallas al Mérito Educativo, siguen siendo los candidatos propuestos por ANDES 21 de Junio los que consiguen imponerse en las votaciones gremiales, lo que no deja de ser una señal de su permanente implantación dentro del magisterio y de su continuado prestigio ante la sociedad.

\section{La conferencia episcopal de Medellín}

El Concilio Vaticano II se desarrolló entre 1963 y 1965. Lo impulsó el Papa Juan XXIII y lo llevó a su culminación su sucesor, Paulo VI. Marcó una importante renovación de la Iglesia Católica, en dirección a salir al encuentro de los cambios propios del mundo moderno y de acercamiento al sentir y al sufrir de los fieles. Señaló como prioridad la evangelización y la labor pastoral, de tal modo que la Iglesia-institución se pusiera al servicio de la Iglesia-misión. La misión es anunciar la buena nueva y denunciar el pecado en el mundo; ayudar al advenimiento y construcción del Reino de Dios entre los hombres. No simplemente esperar al Día del Juicio Final, sin hacer nada que contribuya a su 
concreción histórica. Se desprende de ahí que las bases de la Iglesia universal sean las comunidades de base.

La Iglesia católica analiza su papel en el mundo y para el mundo. La palabra "iglesia" significa "pueblo que peregrina", es decir, grupo de hombres y mujeres que para ser iglesia no se salen de la historia. Insertarse en ella y en la sociedad con sus problemas y contradicciones es tarea prioritaria, pues el pecado es ante todo la injusticia que hay. La paz debe basarse en la justicia. Surge del Concilio una nueva sensibilidad social y un renovado compromiso hacia los pobres y los oprimidos. Se retoma el espíritu de los primeros siglos de cristianismo, el de la vivencia comunitaria y de la persecución.

El mensaje del Concilio Vaticano II fue reiterado y puntualizado en la encíclica papal "Populorum progressio" en 1967. En agosto de ese mismo año se realizó el encuentro de Obispos del Tercer Mundo que lanzó un pronunciamiento en el que se reflejaba la nueva conciencia eclesial. Si la Iglesia se volcaba al mundo, su postura se radicalizaba ahí donde el mundo era pobre y oprimido. No podía ser de otra forma. En enero de 1968 uno de los obispos brasileños, Monseñor Fragoso, exponía: "El Evangelio es la buena nueva de la liberación de todos los hombres en Cristo... Cristo no vino sólo a liberar al hombre de sus pecados; vino a liberarlo de las consecuencias de su pecado. No tengamos miedo de ser llamados "subversivos", si nuestra conciencia nos dice que estamos tratando de "subvertir" un desorden moral que está ahí."

Entre agosto y septiembre de 1968 se celebró la Segunda Conferencia del Episcopado Latinoamericano en Medellín, Colombia. Los obispos allí reunidos constataban que el continente latinoamericano "vive un momento decisivo de su proceso histórico". Había que estar atento a "los signos de los tiempos". No se podía permanecer indiferente o al margen. No, cuando estaba en juego la emancipación de América Latina, la liberación de sus pueblos. La miseria, concluían, "es una injusticia que clama al cielo".

Su Santidad Pablo VI, en el discurso de saludo y apertura sostenía "nuestra fuerza está en el amor". El Papa puntualizaba que "la transformación profunda y previsora de la cual en muchas situaciones actuales tiene necesidad la sociedad, la promoveremos amando más intensamente y enseñando a amar". Pero a este propósito el Pontífice se preocupó de ser específico: "ni el odio ni la violencia son la fuerza de nuestra caridad. Entre los diversos caminos hacia una justa regeneración social, nosotros no 
podemos escoger ni el del marxismo ateo, ni el de la rebelión sistemática, ni tanto menos el del esparcimiento de la sangre y el de la anarquía."

En su mensaje a los Pueblos de América Latina, la Conferencia de Medellín hacía un llamado "a los hombres de buena voluntad a colaborar en la verdad, la justicia, el amor y la libertad". De manera más concreta se definía la misión pastoral en "contribuir a la promoción integral del hombre y de las comunidades del continente". Decía: "estamos en una nueva era histórica. Ella exige claridad para ver, lucidez para diagnosticar y solidaridad para actuar.” Pero esa visión, diagnóstico y acción requerían de datos y de análisis que solamente las ciencias sociales podían proporcionar. Había que recurrir a la economía, la sociología, la antropología, la ciencia política...

El encuentro de la teología latinoamericana con el marxismo teórico era inevitable en ese contexto. No dejaría de estar presente, aunque fuera en forma de diálogo y no de una simple aceptación sin más, en las formulaciones de la teología de la liberación que inspiraría Medellín. Por otro lado, en la vida real de las comunidades y del movimiento liberador se encontraban codo con codo, trabajando juntos, cristianos y marxistas. Las relaciones cotidianas de labor organizativa y de lucha reivindicativa limaban asperezas y desconfianzas mutuas. Por lo general los marxistas aportaban capacidad de análisis y experiencia en el trabajo clandestino, los cristianos capacidad de movilización, de concientización y compromiso personal trascendente. Juntas las dos corrientes eran un torrente social que se volvía incontenible en un continente empobrecido y desigual.

A partir de Medellín y de las elaboraciones de los teólogos de la liberación surgiría un poderoso movimiento de comunidades de base que se constituían en masivos núcleos de organización del campesinado. La "opción preferencial por los pobres" inspiraba su labor pastoral, que se expandía rápidamente. Se desarrollaba como "iglesia popular” y provocaba una importante fractura en el seno de la Iglesia católica latinoamericana, con parte de la jerarquía más tradicionalista y a menudo comprometida con el poder y cercana a las oligarquías locales. Era propio del signo de los tiempos: en una época de luchas sociales y guerras civiles, también los cristianos se dividían y resultaban en bandos opuestos. Los asesinatos de sacerdotes y religiosas, acaecidos sobre todo en Centroamérica, no hacían sino ahondar esa división, cuando el Vaticano ya no vibraba en el espíritu del Vaticano II y de Medellín. Pero la impronta dejada en la sociedad era honda, sobre todo tras el martirio de los jesuitas y de los obispos Romero y Gerardi. 


\section{Las redes de computadoras y la conquista de la luna}

Los historiadores han señalado 1968 como el año en que empezó a operar la interconexión de ordenadores puestos en red. Inicialmente se trató de un proyecto secreto del Pentágono. Conectar las computadoras de las distintas unidades militares en el territorio de Estados Unidos iba a permitir la comunicación más segura y prácticamente instantánea entre ellas. Lo decisivo para los intereses militares, no obstante, estaba en el concepto mismo de una red: ésta carece de un centro definido y la comunicación puede establecerse sin él. En el ambiente de guerra fría esta característica era esencial: en caso de un ataque las fuerzas armadas tendrían capacidad de coordinación y de respuesta aun si la sede del alto mando fuese destruida en el primer golpe. Como ha pasado en otros momentos de la historia moderna de la ciencia y de la técnica, era la investigación con objetivos militares la que conseguía avances que serían después de gran importancia para usos civiles. Los altos presupuestos para investigación y experimentación de que disponen los Ministerios de Defensa hacen a menudo la diferencia.

Un tiempo después, el Pentágono accedió transferir a un grupo de universidades esa tecnología, lo que permitió la interconexión de las bibliotecas universitarias así como el desarrollo en red de algunos proyectos de investigación académica. Era sólo cuestión de tiempo el diseño del lenguaje "html" y el surgimiento de la red mundial de redes o "www", más conocida como la Internet. Pronto habría millones de computadoras en el mundo conectadas entre sí, intercambiando todo tipo de información. Significaría una revolución mundial no sólo por la comunicación entre personas particulares, sino sobre todo por las posibilidades que se abrían para las empresas. Se estaba verificando lo que un japonés bautizó en los años sesenta como "la sociedad de la información". Las grandes empresas usarán la revolución informática para fragmentar su producción en distintos países, coordinando el conjunto de operaciones desde un centro virtual, el cual puede estar en cualquier punto del mundo. Las transferencias electrónicas van a permitir una movilidad instantánea de capitales, para inversión o para especulación, lo cual es una de las bases del proceso actual de globalización capitalista. El arranque de esta intensificación de la mundialización de la economía, llamada globalización, que ha cambiado la vida en el mundo, hay que situarlo en estas primeras experiencias de redes entre computadoras.

La tecnología de internet está muy ligada a otro avance tecnológico; el de los satélites de comunicación. Paralelamente y en conexión con el 
desarrollo de la informática era la exploración del espacio otra prioridad militar, esta vez por medio de la NASA. Las dos superpotencias competían también en ese terreno, en lo que se dio en llamar "la carrera espacial". Los soviéticos llevaban ventaja: habían sido los primeros en poner a un satélite en órbita terrestre (el Sputnik), también en enviar a un ser vivo al espacio y hacerlo regresar (la perrita Laika) así como el primer ser humano, de ida y regreso (el astronauta Gagarin). Ahora los norteamericanos compensaban su atraso con un golpe de efecto espectacular: iser los primeros en colocar un hombre en la luna! Los rusos tratarían de restar importancia al hecho y se centraron en conseguir ser los primeros en situar una estación permanente en el espacio, con largos períodos de permanencia para los astronautas. Pero no pudieron evitar el impacto propagandístico logrado por Estados Unidos, que trasmitió por televisión las imágenes del astronauta Armstrong al momento de descender la escalerilla de su nave y posar su pie en la luna.

Se ha dudado del hecho y se ha especulado si se trató de un montaje producido por la industria cinematográfica. Incluso la famosa frase pronunciada por Armstrong - "es un pequeño paso para un hombre, pero un gran salto para la humanidad" - más parecía sacada de un guión de Hollywood: demasiado perfecta para ser real. Incluso algún que otro escéptico ha señalado que en las imágenes se puede ver ondear la bandera norteamericana, lo que fuera imposible en la luna pues el satélite carece de atmósfera. Independiente de esta polémica, lo cierto es que si Estados Unidos no lo había logrado en esa fecha, estaba muy próximo a hacerlo y en los años siguientes obtendría otros éxitos aún más importantes para la carrera espacial. La conquista de la luna se había convertido para el imaginario colectivo en símbolo de la ilimitada capacidad humana y expandió un gran optimismo en el poder del conocimiento científico y de la tecnología.

En las décadas siguientes la superpotencia estadounidense superaría claramente a su rival soviético en la carrera espacial, no tanto en cuanto exploración del espacio, como en su capacidad de desarrollar nuevos sistemas de armas, ofensivas y defensivas, a modo de un escudo protector. La ventaja norteamericana no estaba tanto en un mejor nivel de sus científicos e ingenieros, como en su capacidad de financiar los montos astronómicos de tal proyecto. La Unión Soviética se arruinó en su empeño de seguir los pasos de su rival en esta doble carrera: la armamentista y la espacial. La conquista de la luna por Estados Unidos era un pequeño paso, en realidad, en comparación con el gran salto que significaría el 
proyecto del escudo antimisiles o "star wars" que lanzó la administración Reagan y que precipitó la ruina soviética. Primeros pasos los de 1968 para constituir a Estados Unidos en la única e indiscutida hiperpotencia militar del planeta, tal como lo ha llegado a ser hoy en día.

A modo de conclusión. Para concluir, una cita obligada, la del historiador y agudo analista Eric Hobsbawm: "En 1968-1969, una ola de rebelión sacudió a los tres mundos o grandes partes de ellos, encabezada esencialmente por la nueva fuerza social de los estudiantes cuyo número se contaba, ahora, por cientos de miles incluso en los países occidentales de tamaño medio, y que pronto se convertirían en millones." Hobsbawm utiliza conscientemente la palabra "rebelión". Considera que ya no estaba en el orden del día la "revolución mundial" como la había entendido la generación de 1917 (la de la revolución rusa); "nadie esperaba ya una revolución social en el mundo occidental". Y constata: "el futuro de la revolución estaba en las zonas campesinas del tercer mundo" pero, "incluso donde la revolución era una realidad o una posibilidad, eseguía siendo universal?" De tal modo, el historiador británico tiende a considerar 1968 más como una página que se cierra, que como una que se abre. "La revuelta estudiantil de fines de los sesenta fue el último estertor de la revolución en el viejo mundo.”

Sin embargo, desde la perspectiva de los otros dos mundos, el socialista y el de los países periféricos, la época aparece preñada de revolución, en el sentido de cambios y transformaciones profundas. Por esto aquí se ha elegido un subtítulo con referencias indirectas a la revolución de 1917, pues recuerda el título del famoso reportaje de John Reed sobre la insurrección de octubre: "Diez días que estremecieron al mundo". Para el caso de 1968 se ha convertido en "Diez acontecimientos que cambiaron el mundo". En una visión seguramente menos eurocéntrica que la de Hobsbawm.

Aquí se ha adoptado tal vez una perspectiva más amplia, incorporando otros hechos significativos acaecidos en dicha coyuntura, lo que permite vislumbrar también ciertos procesos que más bien estaban arrancando su despliegue en 1968. Se ha tratado de mostrar asimismo el aspecto ideológico y cultural que refleja la época y que expande su influencia en los lustros siguientes. Muy distinta a la que predominará veinte años más tarde. Era aquella generación que pintaba en los muros "yankis go home", muy diferente a la que a mediados de los ochenta añadirá sarcástica: “...y, illévennos con ustedes!” Una época cargada tal vez de mucha utopía 
y también, sin duda, de poesía. La que inspiraba a los jóvenes de los sesenta, como el que escribió en una pared del Barrio Latino de París: "Bajo los adoquines está la playa". En nuestra época, la de "otro mundo es posible", hay seguramente necesidad de conocer y apreciar esos tiempos anteriores cuando se pensó con ilusión, pero ilusoriamente, que todo iba a ser posible. Años en que pareció factible el asalto del cielo: que se podría traer el cielo a la tierra y así hacerla habitable. La realidad ha mostrado con terquedad dónde queda el horizonte de lo posible, hoy por hoy; pero también muestra día a día que tenemos los pies sobre el terreno de lo insostenible. Y que habrá que saltar a lo imposible. Algo del espíritu del 68 está haciendo falta para superar esa contradicción.

\section{Biblografía CONSULTADA:}

Brower, D.: Historia del mundo contemporáneo, 1900-2001, Prentice Hall, Madrid, 2002.

CELAM: Los textos de Medellin y el proceso de cambio en América Latina; UCA, San Salvador, 1977.

Clerc, J. - P.: Las cuatro estaciones de Fidel Castro. Una biografía politica; Aguilar, Buenos Aires, 1997.

Fuentes/LaParra: Historia universal del siglo XX. De la Primera Guerra Mundial al ataque a las Torres Gemelas, Síntesis, Madrid, 2001.

García Canclini, N.: Culturas hibridas. Estrategias para entrar y salir de la modernidad; Sudamericana, Buenos Aires, 1992.

Hobsbawm, E.: Historia del siglo XX, Crítica, Barcelona, 2000.

Años interesantes. Una vida en el siglo XX, Crítica, Barcelona, 2003.

Howard, M. (ed.): Historia Oxford del siglo XX, Planeta, Barcelona, 1999.

Martínez C.: Introducción a la bistoria contemporánea, 2 tomos, Istmo, Madrid, 1999.

Nouschi, M.: Historia del siglo XX: todos los mundos, el mundo, Cátedra, Madrid, 1999.

VV. AA.: Iglesia de los pobres y organizaciones populares; UCA, San Salvador, 1979. 